
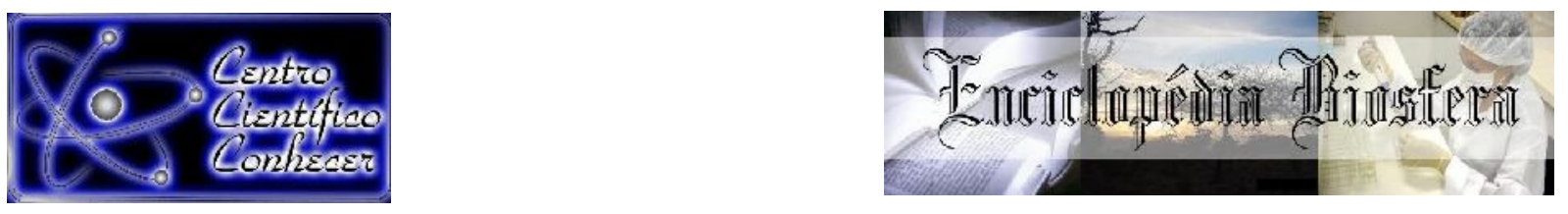

\title{
PANORAMA DO SETOR FLORESTAL BRASILEIRO COM ÊNFASE NO ESTADO DE MINAS GERAIS
}

Gabriel Thales da Cunha1, Isáira Leite e Lopes², Rafael Menali Oliveira ${ }^{3}$, Kalill José Viana da Páscoa ${ }^{4}$, Lucas Rezende Gomide ${ }^{5}$

${ }^{1}$ Engenheiro Florestal pela Universidade Federal de Lavras (UFLA), Lavras-MG, Brasil.

2 Doutoranda do Programa de Pós-graduação em Engenharia Florestal da Universidade Federal de Lavras (UFLA), Lavras-MG, Brasil.

E-mail: isairalopes_moc@hotmail.com

${ }^{3}$ Mestrando do Programa de Pós-graduação em Engenharia Florestal da Universidade Federal de Lavras (UFLA), Lavras-MG, Brasil.

${ }^{4}$ Doutor em Engenharia Florestal no Laboratório de Estudos e Projetos em Manejo Florestal, Lavras-MG, Brasil.

${ }^{5}$ Professor Doutor no Departamento de Ciências Florestais da Universidade Federal de Lavras (UFLA), Lavras-MG, Brasil.

Recebido em: 06/04/2019 - Aprovado em: 10/06/2019 - Publicado em: 30/06/2019 DOI: 10.18677/EnciBio_2019A96

\begin{abstract}
RESUMO
Este estudo teve como objetivo o conhecimento do setor florestal brasileiro com enfoque em Minas Gerais. Para isso, abordou-se o setor florestal desde o seu início com o surgimento das políticas de incentivo aos plantios florestais voltados a produção, passando pelo seu desenvolvimento ao longo dos anos, até chegar no presente momento, em que o Brasil figura entre os principais exportadores de produtos florestais do mundo. Nesse contexto, o estado de Minas Gerais se destaca, por ser líder em florestas plantadas de produção no país, principalmente de Eucalyptus e também na produção de carvão vegetal, o que explica o número de empresas do ramo da siderurgia localizadas em Minas Gerais. Outro ponto favorável ao desenvolvimento dos reflorestamentos no estado é a parceria entre o Instituto Estadual de Florestas e a Associação das Siderúrgicas para o Fomento Florestal, que dá suporte, financeiro e técnico, ao pequeno e médio empreendedor florestal para a implantação dos plantios. É evidenciado também que o setor florestal é um ponto crucial para a elevação dos indicadores socioeconômicos do país, devido a geração de empregos e renda, que impactam diretamente no Índice de Desenvolvimento Humano e no Produto Interno Bruto. Embora o estado de Minas Gerais apresente alguns pontos a serem melhorados, em relação a incentivos governamentais para impulsionar ainda mais o desenvolvimento de florestas, a produção das mesmas deve ser considerada para a geração de riquezas no meio rural, ajudando não só no desenvolvimento socioeconômico do estado, mas também do país.
\end{abstract}

PALAVRAS-CHAVE: indicadores socioeconômicos, incentivos fiscais, produtos madeireiros. 


\title{
OVERVIEW OF THE BRAZILIAN FORESTRY SECTOR WITH EMPHASIS IN THE STATES OF MINAS GERAIS
}

\begin{abstract}
This study aim was to know the Brazilian forestry sector with focus in Minas Gerais. To do so, the forestry sector was approached from its beginning with the advancement of policies to encourage forest plantations focused on production, going through its development over the years, until reaching the present moment, in which Brazil figures among the main exporters of forest products in the world. In this context, the state of Minas Gerais stands out, by being leader in planted production forests in the country, mainly of Eucalyptus and also in the vegetable charcoal production, what explains the number of companies in the steel industry located in Minas Gerais. Another favorable point to the development of reforestation in the state is the partnership between the State Forestry Institute and the Association of Companies for Forest Development, which provides financial and technical support to the small and medium forest entrepreneur for the implantation of the plantations. It is also evidenced that the forestry sector is a crucial point for the elevation of the socioeconomic indicators of the country, due to the generation of jobs and income, that directly impact the Human Development Index and the Gross Domestic Product. Although the state of Minas Gerais presents some points to be improved, in relation to government incentives to further promote the development of forests, their production should be considered for the generation of wealth in the rural, helping not only the socioeconomic development of the state but also the country.
\end{abstract}

KEYWORDS: socioeconomic indicators, tax incentives, timber products.

\section{INTRODUÇÃO}

Até o início dos anos 60, o setor florestal brasileiro era considerado pouco expressivo, pois naquela ocasião o governo não tinha interesse no desenvolvimento da atividade florestal no país, dessa forma, o manejo de florestas, tanto nativas, quanto plantadas, era quase insignificante, com baixo emprego de tecnologia e gestão de projetos. Uma quantidade irrisória de empregos era gerada e grande parte do maciço florestal era importado, além de que, boa parte dos produtores não se interessavam em investir grandes quantias em seus projetos, principalmente pelos riscos associados ao longo período de retorno do capital pelos empreendimentos florestais (SILVA, 2018).

A partir de 1965, ano em que as políticas governamentais começaram a incentivar os reflorestamentos, ocorreu uma mudança significativa no setor, proporcionando um crescimento nas áreas de florestas plantadas (MEDEIROS et al., 2017). Gêneros exóticos como o Eucalyptus e o Pinus foram os primeiros a se destacar nas regiões Sul e Sudeste do país, apresentando alto grau de desenvolvimento, boa adaptação aos fatores edafoclimáticos e qualidade de madeira considerável (ANTONÂNGELO; BACHA, 1998).

Embora essa mudança no cenário florestal brasileiro tenha sido extremamente benéfica ao setor, existiam deficiências relacionadas a baixa produtividade e pouco conhecimento silvicultural das espécies, o que fazia com que a atividade ainda apresentasse empecilhos para que finalmente deslanchasse no Brasil (HORA, 2015). 
Considerando que em países de clima temperado a rotação cultural de gêneros como, Pinus e Eucalyptus, é em média de 50 anos, os solos e clima brasileiros se destacam pela produção de altos volumes de madeira em menos de sete anos. Dessa forma, o desenvolvimento da silvicultura no Brasil somado às condições edafoclimáticas ideais, promovem, além de aumento na produtividade, redução na idade de rotação das florestas, minimizando, ao final do processo, os custos de produção da matéria-prima (BRASIL, 2011).

Entretanto, com o fim dos incentivos fiscais, no final dos anos 80, ocorreu uma redução significativa nos reflorestamentos, afetando diretamente a oferta de matériaprima para os setores industriais. Diante disto, os reflorestamentos começaram a ser financiados por recursos próprios das empresas de base florestal de modo a tornaremse autossuficientes (CASTANHO FILHO et al., 2011).

Entre 1991 e 2001, a atuação do Banco Nacional de Desenvolvimento Econômico e Social (BNDES) começou a se sobressair pelo fato da disponibilização de cerca de US\$ 435 milhões, em recursos destinados aos empreendimentos e pesquisas florestais brasileiras (EISFELD et al., 2017). A partir deste momento, o setor florestal no Brasil teve o BNDES como principal financiador da atividade, apoiando as indústrias que têm nas florestas a matéria-prima essencial para a geração de empregos e riquezas para o país (COSTA, 2016).

Outra importante modalidade de subsídio que ajudou o setor florestal a prosperar no Brasil é o fomento, que consiste em um instrumento estratégico para a inserção dos produtores rurais na cadeia de produção de madeira. Esse subsídio além de dar apoio financeiro ao produtor, promove benefícios às áreas rurais e também favorece as empresas que terão matéria-prima para o seu consumo em um raio econômico viável aos seus gastos com logística, sem a necessidade de adquirir novas áreas para o plantio (CARVALHO et al., 2016).

Atualmente, o fomento florestal é promovido por grandes empresas do ramo de papel, celulose, siderurgia e painéis de madeira reconstituída. Os programas se destacam, cada vez mais, pelo fato de promover uma alternativa ao uso de áreas que eram deixadas de lado pela agricultura, em pequenas e médias propriedades rurais. Com o financiamento gerado por esses tipos de programa, o produtor, tem acesso a tecnologias avançadas, materiais genéticos mais adaptados à sua área, assistência técnica necessária, insumos para a produção, além da garantia da compra de parte e/ou toda a produção pela empresa que Ihe ofereceu auxílio na produção (EISFELD et al., 2017).

Esta revisão bibliográfica teve como objetivo abordar o setor florestal brasileiro devido a sua relevância para o desenvolvimento social, ambiental e econômico nacional, com enfoque no estado de Minas Gerais, considerando sua competitividade ao longo dos anos e seus efeitos na geração de riquezas para o país; avaliar a situação atual do setor florestal mineiro; identificar os efeitos macroeconômicos na dinâmica de produção de madeira e também os efeitos do mercado cambial na exportação e suas relações frente a ampliação dos investimentos. 


\section{MATERIAL E METODOS}

A busca dos artigos relacionados ao tema foi realizada a partir de 2015, com ressalvas para as referências clássicas e de grande importância para assunto em questão. Utilizando como fonte de busca as bases bibliográficas Scielo, Google Scholar, além dos relatórios governamentais informativos. As palavras chaves mais utilizadas foram "setor florestal brasileiro", "fomento florestal", "florestas em Minas Gerais", "engenharia florestal", "incentivos fiscais", "histórico florestal", "consumo de madeira", "indicadores socioeconômicos", "indústria siderúrgica" e "empreendimentos florestais". A seleção dos trabalhos citados foi feita com base na relevância da informação disponível e sua contemporaneidade.

\section{Números do setor florestal brasileiro}

\section{RESULTADOS E DISCUSSÃO}

O setor florestal brasileiro demonstra força no cenário desfavorável macroeconômico, pelo qual o país passa nesta segunda metade da década de 2010 . Uma vez que, o Produto Interno Bruto (PIB) do setor alcançou a marca de $R \$ 73,8$ bilhões, o que equivale a $1,1 \%$ do PIB nacional e $6,1 \%$ do PIB Industrial brasileiro, de acordo com o relatório anual do lbá (2018).

De acordo com o Relatório de Avaliação Global dos Recursos Florestais da Food and Agriculture Organization of the United Nations (FAO, 2015), a área mundial recoberta por florestas é de aproximadamente 3.999 milhões de hectares, o que corresponde a cerca de $30,6 \%$ da superfície terrestre. Desse total, apenas $7 \%$ corresponde às plantações florestais, porém, o crescimento anual é superior a 110 milhões de hectares desde 1990.

Neste contexto, o Brasil é responsável pela segunda maior área recoberta por florestas no mundo (aproximadamente 493 milhões hectares, somando áreas nativas e plantadas), que corresponde a $12 \%$ da superfície florestal mundial, ficando atrás apenas da Rússia, que tem 814 milhões hectares (FAO, 2015). Com uma área de 7,84 milhões de hectares de reflorestamento, menos de $1 \%$ da área total do país, o setor brasileiro de árvores plantadas é responsável por mais de $90 \%$ de toda a madeira produzida para fins industriais e é um dos segmentos com maior potencial de contribuição para a construção de uma economia verde (IBÁ, 2018).

Quase $50 \%$ das florestas tropicais úmidas naturais existentes no mundo estão localizadas na América, sendo que, desse total, aproximadamente $80 \%$ pertencem a região amazônica $(67,98 \%$ no Brasil e o restante distribuídos pela Colômbia, Peru, Equador, Venezuela, Bolívia, Guiana, Suriname e Guiana Francesa), de acordo com Aragón (2018). O autor ainda afirma que aproximadamente $71 \%$ das florestas nativas nacionais correspondem a floresta Amazônica e o restante, por Cerrado, Caatinga, Mata Atlântica, Pantanal e Pampas. Dessa forma, pode-se dizer que a ampla extensão territorial recoberta por florestas, faz com que o Brasil seja considerado como um dos grandes atores nas questões ambientais estratégicas no mundo, além do enorme potencial produtivo de produtos oriundos da floresta.

A área de florestas plantadas foi aproximadamente 5,7 milhões de hectares referente a plantios de Eucalyptus, localizados nos estados de Minas Gerais, São Paulo e Mato Grosso do Sul, que juntos apresentaram cerca de $56 \%$ da área plantada 
nacional. Já a área de Pinus foi de aproximadamente 1,6 milhão de hectares com maior concentração no sul do país, devido a boa adaptação do gênero à região, destacando os estados do Paraná e de Santa Catarina que somados representaram $76 \%$ das áreas de plantio do gênero no Brasil (IBÁ, 2017).

Ainda de acordo com os dados do anuário do lbá, nos últimos cinco anos a área plantada de Pinus apresentou uma taxa de queda de $0,7 \%$ ao ano, já o Eucalyptus demonstrou crescimento da área plantada de $2,4 \%$ ao ano. Cenário que mostra uma substituição dos plantios de Pinus por Eucalyptus, podendo ser evidenciado pelo aumento das áreas plantadas do Mato Grosso do Sul, que plantou 400 mil hectares de Eucalyptus nos últimos cinco anos.

No momento atual, a maior concentração de empreendimentos florestais está localizada no Estado de Minas Gerais (35\%), seguido por São Paulo (16\%), sendo que o estado de Minas Gerais é o principal produtor de Eucalyptus, com aproximadamente $24 \%$ do total nacional, seguido pelo estado de São Paulo, com 17\%. Esse agrupamento é atribuído a ocorrência das principais indústrias de siderurgia e celulose/papel na região Sudeste do país (IBÁ, 2017; MARTINS et al., 2018).

\section{Minas gerais e o setor florestal}

O estado de Minas Gerais, localizado na região Sudeste do país, é o quarto maior em extensão territorial $\left(586.852,35 \mathrm{~km}^{2}\right)$ e o segundo mais populoso da nação, com aproximadamente 19,5 milhões de habitantes (BRASIL, 2017a). Com área correspondente a $6,9 \%$ do território nacional, o estado possui a maior malha rodoviária do país, com aproximadamente 269.546 quilômetros de rodovias e também faz divisa com Espírito Santo, Rio de Janeiro, São Paulo, Goiás, Mato Grosso do Sul e Bahia. Essa característica é extremamente favorável ao escoamento de toda a sua produção, o que combinada com a sua vasta malha de rodovias compensam o fato de Minas não ter comunicação direta com o oceano e consequentemente com os portos nacionais (BRASIL, 2015b).

O setor florestal do estado é responsável pela maior área de florestas de produção plantadas no Brasil. Isso se deve, principalmente, ao fato de grandes empresas do ramo da metalurgia estarem alocadas no amplo parque industrial de Minas Gerais, que conta também com indústrias processadoras de celulose e de painéis de madeira reconstituída (AMS, 2015). Como exemplo, das principais empresas que movem a economia mineira pode-se citar a Cenibra, do ramo da celulose, e a Arcelor Mittal, da metalurgia. Dessa forma, a oferta por madeira do estado deve ser diversificada, podendo atender às múltiplas demandas que o setor necessita.

\section{Ensino e Pesquisa Florestal}

De acordo com dados do BRASIL (2012), em 2012, o Brasil possuía 30.718 cursos de ensino superior presenciais. O estado de Minas Gerais ofertava, em 2012, 3.177 cursos de graduação, sendo o segundo maior estado brasileiro em oferta de cursos, atrás somente de São Paulo. O início do curso de engenharia florestal no Brasil veio junto com a criação da Escola Nacional de Florestas e a oferta do primeiro curso de ensino superior, que foi instalado na Universidade Federal de Viçosa em meados de 1960 (CAPDEVILLE, 2007). 
Atualmente, existem 61 cursos de bacharelado em engenharia florestal no país, distribuídos em 60 instituições de ensino. Desse total, Minas possui 6 instituições de ensino, ficando atrás somente do Pará, que tem 7 universidades que ofertam 0 curso (BRASIL, 2016c). As instituições públicas de ensino superior predominam com 49 cursos na área de engenharia florestal. Juntas as regiões Norte e Sudeste são responsáveis por cerca de $49 \%$ da oferta nacional em cursos de graduação relacionados às ciências florestais. Ainda de acordo com dados do BRASIL (2016c), a graduação em engenharia florestal no Brasil, em 2015, tinha 13.609 matriculados, sendo que 1.517 estavam concluindo o curso (BRASIL, 2015d).

Entre os cursos de engenharia florestal do país, a Universidade Federal de Lavras e a Universidades Federal de Viçosa se destacam por sua tradição em pesquisa e profissionais inseridos no mercado (BRASIL, 2015e). Em relação a pós-graduação do curso de engenharia florestal, o país possuía, em 2015, um total de 1.533 alunos de pós-graduação, sendo 643 alunos de doutorado e de 890 mestrado (considerando também o programa de mestrado profissional), além de 122 doutores e 337 mestres já titulados. O estado de Minas Gerais sozinho é responsável por abrigar $26 \%$ dos alunos de doutorado, $25 \%$ de mestrado e $31 \%$ de mestrandos profissionais (BRASIL, 2016a).

Diante deste cenário, é importante evidenciar que apesar do crescimento neste setor educacional, o Brasil resulta em uma quantidade insuficiente de cursos de Engenharia Florestal. Portanto, o meio acadêmico florestal ainda necessita de maiores investimentos provenientes do poder público e privado e também do apoio governamental (ARRIVABENI et al., 2016).

\section{Principais espécies plantadas em Minas Gerais}

Em Minas Gerais, a silvicultura é compreendida como uma atividade de grande relevância para o desenvolvimento econômico do estado, principalmente a partir do reflorestamento de espécies do gênero Eucalyptus e Pinus (RIBEIRO et al., 2018). Estes gêneros foram escolhidos por grande parte dos produtores do estado para os seus empreendimentos, uma vez que apresentam similaridades edafoclimáticas com as suas regiões de origem (REIS et al., 2017; OLIVEIRA et al., 2017). Desde então, as pesquisas e os tratos silviculturais para os dois gêneros sofreram um demasiado avanço e foram se adequando cada vez mais, para a região mineira.

As áreas reflorestadas por Eucalyptus e Pinus, especificamente em Minas Gerais, resultam em 1,49 milhão e 52 mil, respectivamente. O que representa 19, 97\% dos plantios do território nacional, caracterizando o estado como líder na produção de florestas plantadas do Brasil (AMS, 2015).

Em relação ao gênero Pinus, as espécies mais recorrentes em empreendimentos mineiros são aquelas que tem origem no Caribe e na América Central (tropicais), sendo a espécie caribeae com as variedades caribaea e hondurensis, as com maior área plantada no estado (MONTEIRO et al., 2016).

Nos últimos anos houve uma estabilização nos plantios em Minas Gerais e São Paulo, além de um elevado crescimento nos reflorestamentos do Mato Grosso do Sul devido a política de incentivos favoráveis a expansão do estado e também às empresas que estão alocadas no estado, como a Eldorado e a Fibria, que estão expandindo os seus empreendimentos. Um outro fator que também deve ser levado em consideração 
é o valor da terra, que no estado é mais baixo, quando comparado ao de Minas Gerais (IBÁ, 2016).

O estado de Minas Gerais é o responsável direto por aproximadamente um quarto dos plantios do gênero Eucalyptus de todo Brasil. Grande parte dessa madeira vai para outros estados, por conta da diminuição na demanda das siderúrgicas e metalúrgicas de Minas Gerais. Fato que afeta diretamente o preço da matéria-prima florestal, que é vendida a preços mais baixos, para compensar os altos valores relacionados ao transporte e a logística envolvida na operação (IBÁ, 2016).

Outra espécie é mogno africano (Khaya ivorensis), introduzido no Brasil em 1973, por meio de um estudo conduzido pela Embrapa Amazônia Oriental, o mesmo apresentou boa adaptação às condições brasileiras, o que deu suporte aos crescentes empreendimentos que estão localizados em grande parte do estado de Minas Gerais, embora em algumas áreas do estado seu cultivo é restrito às condições edafoclimáticas (CASAROLI et al., 2018).

Ainda em relação a espécies consideradas nobres, outra espécie é o cedro australiano (Toona ciliata) que pode ser uma alternativa ao uso da madeira de cedro brasileiro (Cedrella odorata), visto que possui características semelhantes as madeiras consideradas nobres pelo mercado consumidor (LIMA et al., 2015). Os plantios de cedro australiano estão localizados na região Sudeste do país, onde tem apresentado bom desenvolvimento evidenciado pelas altas taxas de crescimento (IBÁ, 2016).

\section{Competitividade e atratividade do estado para a produção de madeira Histórico de políticas fiscais}

A alta demanda pela matéria-prima florestal, gerada no período pós década de 60, fez com que o material lenhoso despertasse o interesse econômico dos produtores. A madeira utilizada naquela época era, em grande parte, proveniente de desmatamentos ilegais das regiões de Cerrado, Mata Atlântica e das florestas de Araucárias do sul do país (MOREIRA et al., 2017). A matéria-prima florestal que movimentava as indústrias que necessitavam de lenha e carvão era proveniente da expansão da agricultura no país. No caso das indústrias de serrados, a madeira era proveniente das Araucárias, que apresentam um fuste retilíneo e sem nós. E os plantios de espécies exóticas atendiam a demanda proveniente da ampliação das linhas férreas do estado de São Paulo, que necessitavam de dormentes e biomassa para energia (LADEIRA, 2002).

Dessa maneira, entre as décadas de 1940 e 1950, alguns gêneros exóticos começaram e ser introduzidos no Brasil, com o intuito principal de se obter quantidades maiores de madeira por meio de reflorestamentos. A partir desse momento, o gênero Eucalyptus começou a se destacar, por conta de sua boa adaptação ao clima e solos brasileiros. Porém, ao final da década de 50, os plantios de florestas homogêneas ainda eram muito pequenos e se concentravam basicamente no estado de São Paulo. Esse agrupamento se devia, principalmente, pelo fato de que grande parte dos consumidores desse tipo de matéria-prima estavam alocados no estado (ARAUJO et al., 2017).

Com o passar dos anos, as indústrias consumidoras de madeira foram aumentando, porém, os plantios não acompanharam 0 crescimento. Consequentemente houve um aumento no desmatamento dos remanescentes nativos 
do país, o que acendeu um sinal de alerta para o governo vigente (DEAN, 1996). Uma nova política considerando o reflorestamento, como uma alternativa aos frequentes desmatamentos das florestas nativas, começou a ser estabelecida. Neste sentido, o estabelecimento do programa de incentivos fiscais aos proprietários, na década de 60, promoveu a silvicultura de plantios comerciais de forma intensiva, principalmente nas regiões Sul e Sudeste (MEDEIROS et al., 2017).

Visando modificar o atual cenário, algumas medidas políticas foram tomadas, a começar pela Lei no 4.771 , de 1965, a qual era baseada na promulgação do Código florestal, que tinha como objetivo, tornar obrigatório o ato de reposição das áreas desmatadas e também conceder aos produtores incentivos fiscais para quem iniciasse a produção de florestas em sua propriedade (RORIZ; FEARNSIDE, 2015).

A criação simultânea de mecanismos de incentivos, como o Código Florestal/1965, a Lei 5.106/1966, que regulamentou os incentivos fiscais determinados no Código Florestal de 1965 e o Instituto Brasileiro de Desenvolvimento Florestal (IBDF/1967) possibilitaram a expansão da área plantada com dinheiro público e o financiamento subsidiado às unidades industriais com escalas mínimas crescentes de produção e incentivo à pesquisa pública no setor de silvicultura. Também, propiciaram uma articulação das áreas florestais e industriais que firmou a relação de grandes fornecedores verticalizados para o mercado internacional de papel e celulose, além do setor siderúrgico brasileiro (SILVA, 2018).

Então, com esses primeiros incentivos a silvicultura de espécies exóticas começou a se expandir, de forma que os reflorestamentos do país tiveram um aumento expressivo e sua participação no mercado demonstrava que o setor em breve se fortaleceria (HORA, 2015).

Com o objetivo de complementar as políticas de incentivo que foram criadas em um primeiro momento, instituiu-se o Fundo de Investimentos Setoriais (FISET), em 1974, uma das medidas do Programa Nacional de Desenvolvimento (PND) que previa regular os capitais nos setores de pesca, turismo e florestal. A concessão de incentivos ocorreu de modo irrestrito, entre 1966 e 1976. Diante disso, foi editado o Decreto 79.046, visando a regulação de incentivos fiscais, em que foi estabelecido que a concessão de incentivos seria direcionada somente para regiões prioritárias para o reflorestamento e/ou distritos florestais-industriais (HORA, 2015).

No ano de 1976, devido aos vários incentivos governamentais que visavam a produção de florestas, o Brasil era o quarto país que mais fornecia subsídios aos plantios florestais, ficando somente atrás da China, União Soviética e Estados Unidos. Nesse contexto, os projetos vinculados às políticas vigentes de incentivos resultaram no plantio de aproximadamente 6,2 milhões de hectares de florestas entre os anos de 1967 e 1986 (LEÃO, 2000).

Porém, após alguns problemas de financiamento e incentivos sendo aplicados de formas indevidas, o FISET passou por uma severa redução a partir de 1983, o que culminou na interrupção das atividades do fundo no ano de 1988. Em consequência disso, os plantios florestais sofreram uma atenuação considerável nos anos seguintes, o que afetou diretamente a oferta de madeira que supria a crescente demanda da indústria florestal. Indiscutivelmente, o fundo beneficiou o setor florestal brasileiro (BURNETT, 2017). 
De acordo com Kengen e Graça (1999), os reflorestamentos conduzidos no período pós FISET, foram fomentados principalmente por empresas, em geral, do ramo de papel e celulose, que tinham sido beneficiadas previamente pelo fundo e no momento possuíam dinheiro para investir, e também por entidades de governos estaduais. Logo no início dos anos 90, quem assumiu o papel de financiamento das florestas no Brasil foi o Banco Nacional do Desenvolvimento Econômico e Social, que começou a disponibilizar recursos aos empreendimentos. Em um período de 10 anos (1991 e 2001), o BNDES despendeu aproximadamente US\$ 435 milhões tanto para os próprios reflorestamentos, como também, para a pesquisa que evolui significativamente até 0 atual momento.

Em 2002, o Ministério do Meio Ambiente (MMA), por meio do Programa Nacional de Florestas, estabeleceu o PROPFLORA, plano que teve como principais objetivos a oferta de apoio tecnológico adequado e qualificação da mão-de-obra para a implantação de florestas comerciais em propriedades de pequeno e médio porte. $O$ Programa de Plantio Comercial e Recuperação de Florestas continua em vigência até os dias atuais (HORA, 2015).

Á partir de uma ação em conjunto, do Ministério da Agricultura, Pecuária e Abastecimento (MAPA) e do MMA, foi implementada uma nova linha de crédito ofertada pelo Programa Nacional de Fortalecimento da Agricultura Familiar (PRONAF), que foi designada aos agricultores familiares de modo a financiar a implantação de florestas no país. O PRONAF despontou objetivando o reflorestamento e a silvicultura para produtos madeireiros e não madeireiros, energia renovável e a recuperação de áreas de preservação ambiental (HORA, 2015).

Pode-se dizer que os incentivos governamentais para a produção de florestas no país foram os mais variados possíveis, e embora alguns não tenham atingidos os seus objetivos principais, nota-se que, de fato, os plantios voltados a produção e a conservação apresentaram um significativo crescimento desde a década de 60 até o atual momento. Outro importante fator, o qual pode ser citado é que embora a política florestal tenha sido explícita no país, diversas ações tomadas por outros setores da economia refletiram diretamente nas florestas (KENGEN; GRAÇA, 1999).

\section{Programas estaduais de subsídio florestal em Minas Gerais}

Minas Gerais destaca-se dentre os outros estados como um dos precursores na implementação de programas públicos de fomento no país, em que grande parte dos programas despontaram na década de 1980 (BASSO et al., 2012). Uma vez que possui muitos anos de tradição, em comparação aos outros estados, o mesmo possui a estratégia de fomento mais completa que atende às diferentes necessidades de cada produtor (fomento ambiental ou de produção), sendo o único que permite a distribuição de insumos e tem um programa específico para recuperação de áreas degradadas com espécies nativas (EISFELD et al., 2017).

Os programas de fomento florestal têm contribuído com um aumento significativo da atividade de reflorestamento, principalmente por meio do programa estabelecido pelo Instituto Estadual de Florestas (IEF) em conjunto com a Associação das Siderúrgicas para o Fomento Florestal (ASIFLOR), que abrange diversas regiões de modo a propiciar o desenvolvimento socioeconômico do estado (REZENDE et al., 
2008). Despertando o interesse de muitas empresas, como por exemplo Cenibra, Suzano, Veracel, Klabin e International Paper, que firmaram parcerias com pequenos e médios produtores rurais. Essa iniciativa privada tem sido responsável por parte do crescimento da área plantada (HORA, 2015), uma vez que mais produtores têm sido atraídos com base em benefícios como garantia de renda (BASSO et al., 2012).

Neste contexto, cabe ressaltar que o fomento florestal público tem como vantagem a negociação da produção conforme as melhores condições do mercado, logo o plantio não é condicionado a uma determinada empresa. De modo geral, o suporte dado aos produtores rurais por meio desses programas, caracterizam-se pelo fornecimento de mudas, insumos e assistência técnica gratuita (BASSO et al., 2012).

É notória que além da importância do fomento florestal na economia da região, o mesmo é responsável pelas alterações no ambiente que podem consistir em impactos positivos e negativos. Estudos sobre os impactos ambientais são comuns em projetos florestais de âmbito empresarial diante das exigências para fins de licenciamento ambiental, entretanto, ainda são necessários estudos científicos que visam a mitigação de impactos negativos e potencialização dos positivos (VALDETARO et al., 2015).

\section{Indicadores Socioeconômicos de Minas Gerais}

Dentre os indicadores socioeconômicos tem-se o Produto interno bruto (PIB) que mensura a relação da riqueza produzida por habitante em uma determinada região com base em somente aspectos econômicos (VIEIRA et al., 2017). No ano de 2014, o PIB do estado de Minas Gerais foi de aproximadamente 516 milhões de reais, representando $8,9 \%$ do total nacional, ficando atrás somente dos estados de São Paulo e Rio de Janeiro. Além de apresentar um comportamento crescente desde o ano de 2010 (BRASIL, 2016b). Entretanto, o estado de Minas Gerais, mesmo sendo destaque em comparação aos outros estados com base no PIB, demonstra grandes disparidades entre seus municípios e regiões (VIEIRA et al., 2017).

Outro indicador é o Índice Firjan de Desenvolvimento Municipal (IFDM), que abrange as áreas de emprego, renda, educação e saúde. Estes, quando analisados em conjunto representam a qualidade do serviço público na realidade de vida dos cidadãos. Em Minas Gerais constatou-se uma forte relação entre o esforço fiscal e o desenvolvimento, em que seus municípios com maior arrecadação de recursos, também obtiveram um nível maior de desenvolvimento socioeconômico (VIEIRA et al., 2017).

É evidente que os programas de fomento florestal podem proporcionar, de forma direta, a diminuição da taxa de desemprego e o aumento na renda dos pequenos e médios produtores (VALVERDE, 2001). De acordo com o lbá (2016), o Brasil atingiu uma taxa de desemprego de $9,0 \%$ no último trimestre de 2015 e o índice só está crescendo nos últimos meses.

O setor florestal, em 2018, foi responsável pela geração direta de aproximadamente 508 mil empregos em todo o país (IBÁ, 2018). Considerando somente essa estimativa, foram injetados, na economia brasileira, cerca de 9 bilhões de reais. De acordo com algumas projeções do BRASIL (2016b), estima-se que, direta e indiretamente, as florestas brasileiras tenham gerado 3,8 milhões de postos de trabalho. Em 2004, o setor florestal mineiro, incluindo também as áreas de siderurgia, movelaria, 
celulose e papel (que estão diretamente ligadas a florestas de produção), foi responsável pela geração de 1,3 milhões de empregos, diretos e indiretos (VIEIRA et al., 2006).

No quesito arrecadação de impostos, por pertencer a um setor extremamente diversificado, as empresas do setor florestal pagam um valor expressivo de impostos, o que torna a atividade extremamente interessante aos governos (REZENDE et al., 2005). O setor é responsável pelo pagamento de diversos tributos, que chegam a representar aproximadamente $37,78 \%$ da produção em certos casos, e são eles: Imposto de Renda de Pessoa Jurídica (IRPJ); Imposto sobre Circulação de Mercadorias e Serviços (ICMS); Programa de Integração Social / Contribuição para o Financiamento da Seguridade Social (PIS/COFINS); Programa de Formação do Patrimônio do Servidor Público (PASEP); Imposto Sobre Serviços (ISS); Imposto sobre Operações Financeiras (IOF) e Imposto sobre a Propriedade Territorial Rural (ITR).

Estima-se que o setor florestal brasileiro arrecadou cerca de $R \$ 11,3$ bilhões de impostos no ano de 2015, o que representa $0,9 \%$ do total arrecadado com imposto pela nação (IBÁ, 2016). Desse total, 9,3 bilhões são referentes à tributação sobre as receitas e lucros, 1,7 bilhão são de tributos sobre a compra de insumos e equipamentos e 300 milhões são referentes aos tributos salariais dos empregados pelo setor. Quanto aos segmentos florestais, o que mais contribuiu para a arrecadação foi o das indústrias de papel, seguida pelas indústrias de painéis de madeira reconstituída.

Em relação a balança comercial, as exportações do setor florestal, no ano de 2015, apresentaram um aumento de 5,9\% em relação ao ano anterior, atingindo a marca de 9 bilhões de dólares. Já as importações tiveram um decréscimo de 31,6\%, em relação a 2014, com cifras aproximadas à 1,3 bilhão de dólares. Dessa forma, a balança comercial do setor de árvores plantadas fechou o ano de $2015 \mathrm{com}$ um saldo de 7,7 bilhões de dólares, sendo um recorde para as florestas nacionais. Esse fato pode ser explicado pelo baixo valor do real em comparação ao dólar, o que resultou no crescimento da produção interna de celulose, acarretando um grande aumento no valor da commodity (IBÁ, 2016).

\section{Aspectos macroeconômicos do setor}

O Brasil destaca-se entre os principais produtores de celulose, papel e painéis de madeira no mundo, com exportações que evidenciam a contribuição para a balança comercial e geram muitos empregos e renda em todas as regiões do País (IBÁ, 2017). Considerando o atual momento que o Brasil vive, o produto interno bruto teve uma nova redução de $-0,8 \%$, pelo sétimo trimestre consecutivo, segundo os dados do BRASIL (2016b).

A inflação brasileira, que é medida pelo Índice Nacional de Preço ao Consumidor Amplo (IPCA), foi de 7,87\% a.a. em 2016, apresentando uma diminuição em relação ao valor de 2015, que foi de 10,67\% a.a., segundo dados do BRASIL (2016b). Nota-se, que é a segunda vez consecutiva que a meta nacional para a inflação é ultrapassada.

O cenário de alta do dólar desde 2015 até o momento atual impulsionou as exportações dos segmentos industriais do setor florestal, como pode-se evidenciar pelo bom momento que as empresas do ramo de celulose e papel vem vivendo (SANTOS et. al, 2016). 
No segundo trimestre de 2016, de acordo com o BRASIL (2016b), a taxa de desemprego atingiu 11,3\%, a maior desde 2012. Esse aumento na taxa de desemprego reflete as incertezas que o mercado interno nacional está sofrendo e o atual momento político do país.

\section{Consumo de carvão}

A produção nacional de carvão vegetal, produto considerado um dos insumos de maior importância no Brasil, em 2015, apresentou um decréscimo tanto na matériaprima proveniente das florestas nativas, quanto das plantadas. De acordo com o Anuário da Produção da Extração Vegetal e Silvicultura (BRASIL, 2016b), o país produziu cerca de 796 mil toneladas de carvão advindo de remanescentes nativos e 5,3 milhões de toneladas de reflorestamentos, demonstrando um decréscimo de $21,9 \%$ e $13,3 \%$ respectivamente, comparados ao ano anterior. Essa queda na produção pode ser explicada principalmente pela menor demanda das indústrias siderúrgicas, que vem sofrendo com a queda brusca no setor automobilístico nacional e, no caso do carvão vegetal proveniente de florestas nativas, pela maior rigidez dos órgãos ambientais na fiscalização das carvoarias.

Ainda de acordo com o BRASIL (2016b), o estado de Minas Gerais produz sozinho cerca de $82,8 \%$ da demanda nacional de carvão vegetal oriundo de florestas plantadas de Eucalyptus, seguido pelos estados do Maranhão e Bahia, que juntos somam somente $11,9 \%$ do montante.

De acordo com o Relatório Anual da Indústria Brasileira de Árvores (IBÁ, 2016), com consumo de 4,6 milhões de toneladas de carvão, o setor registrou uma queda de $13,2 \%$ em relação ao ano anterior, assim como a sua produção. Retração essa que pode ser explicada pela já citada desaceleração do setor automotivo e também pelo fato de produtos como o ferro-gusa, ferro-ligas e aço brasileiros terem perdido a competitividade no mercado internacional, fato este, que se deve principalmente pela demasiada expansão na exportação de aço que a China vem tendo. Dessa forma, as 120 indústrias siderúrgicas brasileiras, que são a base do consumo de carvão vegetal, vêm operando em cerca da metade de suas capacidades produtivas, o que resulta em um excesso de madeira no estado de Minas Gerais, afetando diretamente no preço.

\section{Consumo de celulose e papel}

A crise na economia brasileira e os altos valores assumidos pelo dólar acarretaram em uma diminuição na produção e consumo da maioria dos produtos derivados da madeira, porém essa lógica não se aplica à celulose. O produto foi o único que apresentou variação positiva do ano de 2014 para o ano de 2015 (BRASIL, 2016b). Considerando a produção de toras de madeira para as indústrias de papel e celulose, observa-se uma variação positiva de $6,7 \%$ em relação ao ano de 2014 , produzindo aproximadamente 76 milhões de metros cúbicos.

Cerca de $72,1 \%$ do montante nacional produzido é proveniente dos estados de São Paulo, Bahia, Paraná, Mato Grosso do Sul e Minas Gerais, que sozinhos produzem aproximadamente 55 milhões de metros cúbicos de madeira, suprindo a gigantesca demanda das empresas do ramo da celulose brasileira (BRASIL, 2016b). Destacando- 
se o estado do Paraná, onde o Pinus obteve uma produção mais expressiva, com cerca de $72,3 \%$ do montante total paranaense.

No ano de 2016, o Brasil alcançou a segunda posição no ranking mundial de maiores produtores de celulose, com uma produção de 18,8 milhões de toneladas de pasta celulósica (considerando fibra curta, fibra longa e a pasta de alto rendimento), ficando atrás apenas dos Estados Unidos (IBÁ, 2017)

Além de estar entre os maiores produtores de celulose no mundo, o Brasil também está entre os maiores exportadores da commodity em questão (CORREA, 2018), visto que, em 2016, a produção brasileira de celulose aumentou em $8,1 \%$ comparado ao ano de 2015 e conferiu ao Brasil a elevação em duas posições no ranking de produção da commodity (IBÁ, 2017).

Diferente da produção de celulose, a produção nacional de papel, assim como os outros produtos derivados da madeira, teve um fraco desempenho, ocasionado principalmente pela retração no consumo doméstico de papel para impressão, que apresentou uma redução das vendas de $0,3 \%$ em relação ao ano de 2015 . O montante produzido totalizou 10,3 milhões de toneladas, cerca de 0,2\% menor que em 2015 (IBÁ, 2017).

Algumas variedades de papel, como por exemplo os papéis para embalagens de alimentos e os papéis especiais para a impressão de fotos, obtiveram um crescimento pequeno, porém significativo, de $1,8 \%$ e $2,5 \%$ respectivamente. Isso se deve principalmente ao fato de serem produtos competitivos em qualidade e preço no mercado externo, aumentando assim sua exportação (IBÁ, 2016).

Atualmente o Brasil ocupa a 8 ${ }^{a}$ colocação nos rankings de maiores produtores de papel, sendo que grande parte das empresas brasileiras produtoras de celulose e/ou papel encontram-se próximas ao mercado consumidor nas regiões Sul e Sudeste do País (IBÁ, 2017).

\section{Consumo de madeira sólida}

No ano de 2015, a produção de madeira em tora (sem contar os segmentos de celulose e carvão), foi de 47 milhões de metros cúbicos, sendo $51,5 \%$ de plantios de Eucalyptus e 45,8 de Pinus. O que demonstrou um decréscimo de 9,1\% em relação ao ano anterior. A região Sul do país foi a que mais produziu, destacando-se o estado do Paraná, com 16,4 milhões de 40 metros cúbicos. Minas Gerais foi o quinto maior produtor com 4,6 milhões de metros cúbicos de toras produzidas (BRASIL, 2016b).

O consumo de madeira serrada no Brasil, por conta principalmente da desaceleração da construção civil, apresentou uma significativa queda. No ano de 2015, 7,2 milhões de metros cúbicos de toras foram consumidos internamente, já em 2015 foram apenas 6,4 milhões. Como consequência disso, a produção brasileira de madeira serrada apresentou um recuo de $2,3 \%$ em relação ao ano anterior (IBÁ, 2017).

Beneficiando-se do aumento do dólar, as exportações de madeira serrada no Brasil tiveram um crescimento de $28 \%$ em relação a 2014 , com 1,6 milhão de metros cúbicos exportados. Além disso, a produção de painéis de madeira reconstituída também apresentou um aumento de $8,3 \%$ no ano de 2015. O que demonstra que a alta do dólar é benéfica para alguns segmentos do setor florestal (IBÁ, 2016). 


\section{Consumo de Aço}

O consumo de carvão vegetal no Brasil está diretamente ligado as indústrias siderúrgicas nacionais, onde os principais consumidores estão relacionados com a produção de ferro-gusa, ferro liga e a fabricação de cimento (BRASIL, 2015a). Em 2013, segundo as informações do Instituto Aço Brasil, $10 \%$ da produção brasileira de aço foi realizada com uso de carvão vegetal como redutor, sendo que $88,7 \%$ do carvão vegetal utilizado na produção de aço foi proveniente de florestas plantadas próprias (CARVALHO, 2016). As indústrias que produzem o mineral no país são de dois tipos, que são as produtoras exclusivas de ferro-gusa, e as siderúrgicas que além do ferrogusa produzem também aço e alguns subprodutos (UHLIG et al., 2008). Os principais pólos produtores de ferro-gusa e aço brasileiros estão localizados em Minas Gerais e entre os estados do Maranhão e Pará.

Para que esses minérios sejam produzidos, o carvão vegetal e o coque, são utilizados como combustíveis e agente redutores nos fornos. Dessa forma, obtém-se o carbono da estrutura dos minérios de ferro, que tornam o material mais homogêneo livre de defeitos, como por exemplo as rachaduras. O carvão vegetal, por não apresentar enxofre em sua composição, melhora a qualidade do ferro-gusa e do aço, o que aumenta significativamente o valor final agregado ao produto, porém o coque é mais barato que o carvão vegetal (UHLIG et al., 2008).

De acordo com as estatísticas do Instituto Aço Brasil, existem 29 usinas produtoras de aço no país, que apresentam uma capacidade de produção de 48,9 milhões de toneladas de aço bruto por ano. No ano de 2014, a produção de aço no país foi de 33,9 milhões de toneladas e o consumo aparente de 25,6 milhões apresentando um saldo comercial de US\$2,7 bilhões. Atualmente o Brasil é o 6ํㅡ maior exportador mundial (considerando somente os valores líquidos de exportação e importação), exportando para mais de 100 países (IBÁ, 2016).

\section{CONSIDERAÇÕES FINAIS}

Com os argumentos apresentados nesse estudo, pode-se concluir, em um primeiro momento, que o Brasil figura como um dos principais produtores de matériaprima proveniente de florestas plantadas no mundo, competindo com países como a Rússia, Estados Unidos, Canadá, entre outros. Fato esse que demonstra, certamente, o potencial do setor em relação a geração de riqueza e também como as florestas podem ser um ponto a ser considerado para que o país volte a apresentar crescimento na sua economia.

Ao contrário de alguns estados do Brasil, Minas Gerais apresenta algumas falhas relacionadas às políticas de incentivos fiscais, as quais deixaram de ser priorizadas para o desenvolvimento do setor florestal no estado. Ponto, ao qual, deve ser mais estudado e otimizado, visto que as indústrias visam regiões que oferecem além de infraestrutura e mão-de-obra, também incentivos para o desenvolvimento a longo prazo de seu negócio.

Embora as políticas de incentivo do estado sejam motivo de crítica, pode-se considerar que a parceria entre o Instituto Estadual de Florestas e a Associação das Siderúrgicas para o Fomento Florestal é um ponto a ser elogiado e também implantado em outros lugares do país. A união de um órgão estadual (que oferece suporte técnico 
ao pequeno e médio empreendedor) com as empresas (responsáveis por empregar o capital necessário para o financiamento dos plantios) auxiliam o setor florestal mineiro na tentativa de suprir a sua demanda por madeira ao longo dos anos.

Além disso, ajudam no desenvolvimento das áreas rurais, por conta de empregar investimentos e gerar empregos em regiões antes esquecidas, o que agrega na renda dos pequenos empreendedores rurais. Outro fator a ser evidenciado são as áreas que, em um primeiro momento, eram consideradas improdutivas pela agricultura tradicional, hoje estão sendo "invadidas" pelos plantios florestais. Fato que contribui amplamente ao progresso do setor florestal no estado. Outro ponto a ser levantado é a direta relação entre os aspectos macroeconômicos e o momento político, pelo qual o país passa, com a dinâmica do setor florestal. Nota-se que as indústrias de celulose e papel foram as grandes beneficiadas com a alta do dólar, tendo um considerável aumento em seus lucros no período. Por outro lado, as empresas do ramo da siderurgia tiveram seus plantios florestais afetados, devido ao aumento dos custos relacionados a produção do ferro-gusa, o que tornou o produto mais caro que em outros países. Isso demonstra os diferentes nichos nos quais o setor florestal brasileiro está inserido, e que a variação no dólar pode beneficiar algum ramo, porém prejudicar o outro.

Deve-se considerar também, as perspectivas, que em sua maioria, indicam que a demanda por madeira irá aumentar, como de fato vem acontecendo ao longo dos anos. Com a busca por energias renováveis, e a biomassa florestal sendo uma alternativa, países com boas condições edafoclimáticas e um vasta extensão territorial podem se tornar fundamentais nesse cenário.

Levando em consideração todos esses aspectos, conclui-se que o investimento em empreendimentos florestais no Brasil deve, certamente, ser levado em consideração, visto a quantidade de indústrias do setor, e a sua crescente demanda por matéria-prima florestal, além do auxílio que os programas de fomento podem oferecer aos produtores. No caso de Minas Gerais, deve-se verificar a questão de oferta e demanda, pelo fato de que o mercado no estado pode estar saturado, visto que a demanda tem diminuído consideravelmente nos últimos anos em decorrência da crise no setor da metalurgia e siderurgia. Dessa forma, a produção, em muitos casos, é vendida para outros estados, o que diminui o custo final do produto, por conta dos custos de transporte e logística. O que deve ser verificado é a proximidade do empreendimento com os possíveis consumidores e adequação do produto a demanda que solicitada, não se esquecendo de associar os custos da terra e a capacidade produtiva, que oneram muito o retorno do capital. Além disso, não deve-se deixar de lado as previsões envolvendo as mudanças climáticas, que podem ou não adicionar um desafio extra na gestão desses ativos florestais.

\section{REFERÊNCIAS}

AMS - ASSOCIAÇÃO MINEIRA DE SILVICULTURA. Apresentação: ano base 2015. Disponível em: <http://silviminas.com.br/wp-content/uploads /2015/11/PresentationAMS-portugu\%C3\%AAs-2015.pdf>. Acesso em: 08 jun. 2016.

ANTONÂNGELO, A.; BACHA, C. J. C. As fases da silvicultura no Brasil. Revista brasileira de economia, v. 52, n. 1, p. 207-238, 1998. Disponível em: 
<http://bibliotecadigital.fgv.br/ojs/index.php/rbe/article/download/721/8086>.

Acesso em: 14 jul. 2016.

ARAGÓN, L. E. A dimensão internacional da amazônia: um aporte para sua interpretação / The international dimension of the Amazon: a contribution for its interpretation. Revista Nera, n. 42, p. 14-33, 2018. Disponível em: <http://revista.fct.unesp.br/index.php/nera/article/view/5676>. Acesso em: 29 de fev. 2019.

ARAUJO, V. A. de; GARCIA, J. N.; CORTEZ-BARBOSA, J.; GAVA, M.; SAVI, A. F.; MORALES, E. A. M.; LAHR, F. A. R.; VASCONCELOS, J. S.; CHRISTOFORO, A. L. Importância da madeira de florestas plantadas para a indústria de manufaturados. Pesquisa Florestal Brasileira, v. 37, n. 90, p. 189-200, 2017. Disponível em: <https://pfb.cnpf.embrapa.br/pfb/index.php/pfb/article/view/824>. https://doi.org/10.4336/2017.pfb.37.90.824.

ARRIVABENI, B. S.; CARNEIRO, A. de C. O.; RIBEIRO, G. A. A caracterização do ensino florestal no âmbito brasileiro e espanhol. Enciclopédia Biosfera. v. 13, n. 24, p. 1-14, $2016 . \quad$ Disponível em:< http://www.conhecer.org.br/enciclop/2016b/agrarias/A\%20caracterizacao.pdf>. $\quad$ DOI: https://doi.org/10.18677/EnciBio_2016B_001.

BASSO, V. M.; JACOVINE, L. A. G.; GRIFFITH, J. J.; NARDELLI, A.; ALVES, R. R.; SOUZA, A. L. de. Programas de fomento rural no Brasil. Pesquisa Florestal Brasileira, v. $32, \quad$ n. $71, \quad$ p. 321 - 334, 2012. Disponível em: < https://pfb.cnpf.embrapa.br/pfb/index.php/pfb/article/view/368>. DOI: https://doi.org/10.4336/2012.pfb.32.71.321.

BURNETT, A. A "saga" político-ecológica da algaroba no semiárido brasileiro. Revista de Estudos Sociais, v. 19, n. 38, p. 148-175, 2017. Disponível em: <http://www.periodicoscientificos.ufmt.br/ojs/index.php/res/article/view/5031/html>. DOI: http://dx.doi.org/10.19093/res5031.

BRASIL, Ministério da educação - Secretaria de Educação Superior. Brasília, MEC, 2015e. Disponível em: < http://portal.mec.gov.br/ultimas-noticias/212-educacaosuperior1690610854/172 46 -indicadores-de-instituicoes-e-cursos-estao-disponiveis>. Acesso em: 20 nov. 2016.

BRASIL, Comissão de aperfeiçoamento de pessoal do nível superior. Brasília: CAPES, 2016a. Disponível em: <http://geocapes.capes.gov.br/geocapes2/>. Acesso em: 08 fev. 2017.

BRASIL, Secretaria de assuntos estratégicos da presidência da república. Diretrizes para a estruturação de uma política nacional de florestas plantadas. Brasília, 2011. Disponível em: < http://www.agricultura.gov.br/assuntos/politica-agricola/todas- 
publicacoes-de-politica-agricola/outras-publicacoes/plano-nacional-de-desenvolvimentode-florestas-plantadas.pdf/view>. Acesso em: 11 fev. 2016

BRASIL, Empresa de Pesquisa Energética. Balanço Energético Nacional 2015: Ano Base 2014. Rio de Janeiro: EPE, 2015a. 266 p.

BRASIL, Governo de Minas Gerais - Geografia. Belo Horizonte, 2017a. Disponível em: < http:// www. mg. gov .br/conheca-minas/geografia>. Acesso em: 10 fev. de 2017.

BRASIL, Governo de Minas Gerais - Rodovias. Belo Horizonte, 2015b. Disponível em: < https://www.mg.gov.br/conheca-minas/rodovias>. Acesso em: 02 fev. 2016.

BRASIL, Instituto brasileiro de geografia e estatística. Estatísticas Econômicas. 2015c. Disponível em: <https://agenciadenoticias.ibge.gov.br/agencia-sala-deimprensa/2013-agencia-de-noticias/releases/9880-pevs-2015-valor-da-extracao-

vegetal-e-silvicultura-alcanca-r-18-4-bilhoes-em-2015>. Acesso em: Acesso em: 02 fev. 2017.

BRASIL, Instituto brasileiro de geografia e estatística. Estatísticas Econômicas. 2016b. Disponível em: < http://www.ibge.gov.br/home/estatistica /pesquisas/pesquisas.php>. Acesso em: 01 fev. 2017.

BRASIL, Instituto nacional de estudos e pesquisas educacionais. Sinopses estatísticas da Educação Superior, 2012. Disponível em: <http://inep.gov.br/web/guest/educacao-superior>. Acesso em: 08 fev. 2016.

BRASIL, Instituto nacional de estudos e pesquisas educacionais. Cadastro das instituições de educação superior, 2016c. Disponível em: < http://inepdata.inep.gov.br/analytics/ saw.dll? Dashboard >. Acesso em: 15 dez. 2016.

BRASIL, Instituto nacional de estudos e pesquisas educacionais. Relatório síntese de área: Engenharia Florestal. Brasília: INEP, 2015d. Disponível em: <http://download.inep.gov.br/educacao_superior/enade/relatorio_sintese>. Acesso em: 10 fev. 2016.

CAPDEVILLE, G. O ensino superior agrícola no Brasil. Revista Brasileira de Estudos Pedagógicos, v. 72, n. 172, 2007. Disponível em: http://emaberto.inep.gov.br/index.php/rbep/article/view/1277>. $\quad$ DOI: http://dx.doi.org/10.24109/2176-6681.rbep.72i172.1277

CARVALHO, K. H. A. de; SILVA, M. L. da; LEITE, H. G.; BINOTI, D. H. B.; SILVA, L. F. da. Influência de diferentes funções objetivo em modelos de regulação florestal. Revista Agro@mbiente On-line, v. 10, n. 4, p. 371-380, 2016. Disponível em: <https://revista.ufrr.br/agroambiente/article/view/3367>. http://dx.doi.org/10.18227/1982-8470ragro.v10i4.3367. 
CARVALHO, P. S. L. de; MESQUITA, P. P. D.; MELO, L. P. D. Siderurgia. In: ASSUMPÇÃO, A. (Ed.). Panoramas setoriais: mudanças climáticas. Rio de Janeiro: Banco Nacional de Desenvolvimento Econômico e Social, 2016. p. 63-71. Disponível em: https://web.bndes.gov.br/bib/jspui/handle/1408/7158. Acesso em: 10 fev. 2017.

CASAROLI, D.; ROSA, F. de O.; ALVES JÚNIOR, J.; EVANGELISTA, A. W. P.; BRITO, B. V. de, PENA, D. S. Aptidão edafoclimática para o mogno-africano no Brasil. Ciência Florestal, v. $28, \quad$ n. $1, \quad$ p. 357-368, 2018. Disponível em: https://periodicos.ufsm.br/cienciaflorestal/article/view/31606. http://dx.doi.org/10.5902/1980509831606.

CASTANHO FILHO, E. P.; OLIVETTE, M. P. de A.; ÂNGELO, J. A.; MARTINS, V. A. Elaboração de índice de preços de resinas e aspectos da cadeia produtiva de pínus para o estado de São Paulo, e seu comportamento de janeiro de 2005 a abril de 2011. Informações Econômicas, v. 41, n. 6, p.47-58, 2011. Disponível em: http://www.iea.sp.gov.br/out/LerTexto.php?codTexto=12170. Acesso em: 12 de fev. 2019.

CORREA, D. V. G. Celulose: logística e distribuição internacional. São Paulo: SENAISP, 2018. $75 \mathrm{p}$.

COSTA, M. M. Financiamento para a restauração ecológica no Brasil. In: SILVA, A. P. M. da; MARQUES, H. R.; ROSA, R. H. (Orgs.). Mudanças no código florestal brasileiro: desafios para a implementação da nova lei. Rio de Janeiro: IPEA-Instituto de Pesquisa Econômica Aplicada, 2016. p. 235-260.

DEAN, W. A ferro e fogo. São Paulo: Companhia das Letras, 1996. 484 p.

EISFELD, R. de L.; SOCHER, L. G.; RIBEIRO, C. C. Modelo de fomento florestal nas instituições estaduais nos estados do Sul, são paulo e minas gerais. BIOFIX Scientific Journal, v. 2, n. 2, p. 1-9, 2017. Disponível em: <https://revistas.ufpr.br/biofix/article/view/53230>. DOI: http://dx.doi.org/10.5380/biofix.v2i2.53230.

FAO - FOOD AND AGRICULTURE ORGANIZATION OF THE UNITED NATIONS Global Forest Resources Assessments, 2015. Disponível em: $<$ http://www.fao.org/forest-resources-assessment/current-assessment/en/>. Acesso em: $01 \mathrm{dez} .2016$.

HORA, A. B. da. Análise da formação da base florestal plantada para fins industriais no Brasil sob uma perspectiva histórica. BNDES Setorial, v. 42, p. 383-426,2015. Disponível em: <https://web.bndes.gov.br/bib/jspui/handle/1408/9615>. Acesso em: 25 de mar. 2019. 
IBÁ - INDÚSTRIA BRASILEIRA DE ÁRVORES - Relatório IBÁ 2016. Brasília: IBÁ, 2016. Disponível em: <http://iba.org/images/shared/Biblioteca /IBA_RelatorioAnual2016_.pdf>. Acesso em: 10 jun. 2016.

IBÁ - INDÚSTRIA BRASILEIRA DE ÁRVORES - Relatório IBÁ 2017. Brasília: IBÁ, $2017 . \quad$ Disponível em: <https://iba.org/images/shared/Biblioteca/IBA_RelatorioAnual2017.pdf>. Acesso em: 10 fev. 2017.

IBÁ - INDÚSTRIA BRASILEIRA DE ÁRVORES - Sumário executivo IBÁ 2018. Brasília: IBÁ, 2018. Disponível em: < https://iba.org/datafiles/publicacoes/relatorios/digital-sumarioexecutivo-2018.pdf>. Acesso em: 03 abr. 2018.

KENGEN, S.; GRAÇA, L. R. Forest policies in Brazil. In: PALO, M.; UUSIVUORI, J. (Ed.). World Forests, Society and Environment. Springer Netherlands, 1999. p. 256-265.

LADEIRA, H. P. Quatro décadas de engenharia florestal no Brasil. Viçosa: Sociedade de Investigações Florestais, 2002. 207 p.

LEÃO, R. M. A floresta e o homem. São Paulo: Instituto de Pesquisas e Estudos Florestais, 2000. 448p.

LIMA, K. B.; RITER NETTO, A. F.; MARTINS, M. A.; FREITAS, M. S. M. Crescimento, acúmulo de nutrientes e fenóis totais de mudas de cedro-australiano (Toona ciliata) inoculadas com fungos micorrízicos. Ciência Florestal, v. 25, n. 4, p. 853-862, 2015. Disponível em: http://www.scielo.br/scielo.php?pid=S198050982015000400853\&script=sci_abstract.

DOI: http://dx.doi.org/10.5902/1980509820583.

MARTINS, B. F.; FREITAS, E. C. S. de; ENRIQUEZ, A. G.; MAGALHÃES, J. G. de S.; RIBEIRO, C. A. A. S.; FREITAS, J. P. O. de. Trajetória dos centros de massa da produção brasileira de florestas plantadas entre 1990 e 2012. Advances in Forestry Science, v. 5, n. $3, \quad$ p. 425-430, 2018. Disponível em: <http://www.periodicoscientificos.ufmt.br/ojs/index.php/afor/article/view/6464>. Acesso em: 11 de fev. 2019.

MEDEIROS, G. I. B. de; FLORINDO, T. J.; SCHULTZ, G.; TALAMINI, E. Análise da competitividade da cadeia produtiva de oleresina de Pinus Brasileira. Revista Espacios, v. 38, n. 27, p. 29-41, 2017. Disponível em: http://www.revistaespacios.com/a17v38n27/a17v38n27p29.pdf. Acesso em: 18 de mar. 2019.

MONTEIRO, C. H. B.; FREIRE NETO, A. O. da L.; OLIVEIRA, J. B. X. de; MONTEIRO, L. de S.; IAPICHINI, J. E. C. B.; RODRIGUES, C. F. de C.; FREITAS, J. A. de; FREITAS, J. A. de; PONTINHA, A. de A. S.; LARA, J. H. Mortalidade de Pinus caribaea 
var. caribaea e Pinus caribaea var. hondurensis na produção resineira e pecuária, na região Norte do Minas Gerais, Brasil. Pubvet, v. 10, n. 1, p. 105-110, 2016. Disponível em: http://www.pubvet.com.br/artigo/2299/mortalidade-de-pinus-caribaea-var-caribaeae-pinus-caribaea-var-hondurensis-na-produccedilatildeo-resineira-e-pecuaacuteria-naregiatildeo-norte-do-minas-gerais-brasil. DOI: 10.22256/pubvet.v10n1.105-110. Acesso em: 24 de mar. 2019.

MOREIRA, J. M. M. Á. P.; SIMIONI, F. J.; OLIVEIRA, E. B. de. Importância e desempenho das florestas plantadas no contexto do agronegócio brasileiro. Floresta, v. 47, n. 1, p. 85-94, 2017. Disponível em: https://revistas.ufpr.br/floresta/article/view/47687/31915. DOI: http://dx.doi.org/10.5380/rf.v47i1.47687. Acesso em:

OLIVEIRA, J. S. de.; PRADO FILHO, J. F.; REZENDE, R. A.; SILVA, M. D. da. Análise espacial como suporte ao planejamento ambiental da região do Quadrilátero Ferrífero, Minas Gerais. Geographia Meridionalis, v.3, n. 1, p.134-156, 2017. Disponível em: https://periodicos.ufpel.edu.br/ojs2/index.php/Geographis/article/view/9925/7263, DOI: http://dx.doi.org/10.15210/gm.v3i1.9925.

REIS, L. S. dos; REIS, R. J. dos; GUIMARÃES, D. P.; SILVA, C. H. F. da. Zoneamento agroclimático de cultivos com potencial energético no estado de Minas Gerais. Revista Espinhaço, v. 6, n. 1, p. 50-63, 2017. Disponível em: http://www.revistaespinhaco.com/index.php/journal/article/view/153. Acesso em: 14 de mar. 2019.

REZENDE, J. L. P. de; OLIVEIRA, A. D.; RODRIGUES, C.; Efeito dos tributos no custo de produção, na rotação e na reforma de Eucalyptus spp., Cerne, v. 11, n. 1, p. 70-83, 2005. Disponível em: http://ciflorestas.com.br/arquivos/doc_efeito_spp._2929.pdf. Acesso em: 10 fev. 2016.

REZENDE, J. L. P. de; PÁDUA, C. T. J.; OlIVEIRA, A. D. de; SCOLFORO, J. R. S.; COELHO JUNIOR, L. M. Indicadores de desenvolvimento humano de regiões assistidas por um programa de fomento florestal. Cerne, Lavras, v. 14, n. 3, p. 274-283, 2008. Disponível em:

http://www.ciflorestas.com.br/documentos.php?limit=500\&t=\&palavra $=\&$ area $=>$. Acesso em: 15 jun. 2017.

RIBEIRO, G. B. de D.; ISBAEX, C.; VALVERDE, S. R. A quantitative analysis of forestry sector contribution for the increase of Minas Gerais municipalities revenues. Revista Árvore, v. 42, n. 3, p. e420303, 2018. Disponível em: http://www.scielo.br/scielo.php?script=sci_arttext\&pid=S0100-

67622018000300202\&lng=en\&nrm=iso. DOI: http://dx.doi.org/10.1590/180690882018000300003.

RORIZ, P. A. C.; FEARNSIDE, P. M. A construção do Código Florestal Brasileiro e as diferentes perspectivas para a proteção das florestas. Novos Cadernos NAEA, v. 18, 
n. $2, \quad$ p. $2015.208, \quad$ Disponível em: https://periodicos.ufpa.br/index.php/ncn/article/view/1866/0. DOI: http://dx.doi.org/10.5801/ncn.v18i2.1866.

SANTOS, R. Q.; SOARES, N. S.; SOUSA, E. P. de. Determinantes da Oferta de Exportação de Papel no Brasil. Revista de Estudos Sociais, v. 18, n. 36, p. 88-106, $2016 . \quad$ Disponível em: http://periodicoscientificos.ufmt.br/ojs/index.php/res/article/view/3292. DOI: http://dx.doi.org/10.19093/res.v18i36.3292.

SILVA, T. A. L. da. A apropriação capitalista da Silvicultura no Brasil e sua lógica de produção do espaço. Terra Livre, v. 1, n. 50, p. 159-199, 2018. Disponível em: < http://agb.org.br/publicacoes/index.php/terralivre/article/view/1447/1387>.

UHLIG, A.; GOLDEMBERG, J.; COELHO, S. T. O uso de carvão vegetal na indústria siderúrgica brasileira e o impacto sobre as mudanças climáticas. Revista brasileira de energia, v. 14, n. 2, p. 67-85, 2008. Disponível em: < http://ambienteregionalagulhasnegras.acendebrasil.com.br/media/academicas/v14n02 o-uso-de-carvao-vegetal-na-industria-siderurgica-brasileira-e-o-impacto-sobre-asmudancas-climaticas_1.pdf $>$.

VALDETARO, E. B.; SILVA, E.; SILVA, J. de C.; JACOVINE, L. A. G. Conjugação dos métodos da matriz de interação e do check-list na avaliação quali-quantitativa de impactos ambientais de um programa de fomento florestal. Revista Árvore, v. 39, n. 4, p. 611-622, 2015. Disponível em: <http://www.scielo.br/pdf/rarv/v39n4/0100-6762-rarv39-04-0611.pdf>. DOI: http://dx.doi.org/10.1590/0100-67622015000400003.

VALVERDE, S. R. As plantações de eucalipto no Brasil. Sociedade Brasileira de Silvicultura, São $\quad$ Paulo, 2001. $\quad$ Disponível em:< http://www.sbs.org.br/destaques_plantacoes nobrasil.htm> Acesso em: 5 out. 2016.

VIEIRA, L. A. N.; SOARES, T. S.; CARVALHO, R. M. A.; REZENDE, J. B. Dimensionamento do setor florestal em Minas Gerais. Cerne, Lavras, v. 12, n. 4, p. 389398, 2006. Disponível em: < http://www.ciflorestas.com.br/arquivos/doc_gerais_2845.pdf>.

VIEIRA, M. A.; ABRANTES, L. A.; FERREIRA, M. A. M.; LOPES, J. do V. S. Implications of the tax collection effort on the socio-economic performance of Minas Gerais municipalities. Gestão \& Regionalidade (Online), v. 33, n. 99, p. 21-38, 2017. Disponível em: < http://www.spell.org.br/documentos/ver/46791/implicacoes-do-esforcode arrecadacao-no-desempenho-socioeconomico-dos-municipios-de-minas-gerais/i/en>. DOI: 10.13037/gr.vol33n99.3981. 